\title{
Investigation on the use of chloramphenicol and amoxicillin in snakehead fish (Channa maculata) farming and analysis of those antibiotic residue in muscle samples
}

\author{
Thao V. Ngo ${ }^{1 *}$, Phu Q. Nguyen ${ }^{1}$, Lam D. Ngo $^{2}, \&$ Ngoc V. Ngo ${ }^{2}$ \\ ${ }^{1}$ Faculty of Environment and Natural Resources, Nong Lam University, Ho Chi Minh City, Vietnam \\ ${ }^{2}$ Faculty of Fisheries, Nong Lam University, Ho Chi Minh City, Vietnam
}

\begin{abstract}
ARTICLE INFO
Research paper

Received: March 08, 2018

Revised: May 08, 2018

Accepted: July 05, 2018

\section{Keywords}

Amoxicillin

Chloramphenicol

Dong Nai

LC-MS/MS

Snakehead fish

\section{${ }^{*}$ Corresponding author}

Ngo Vy Thao

Email: ngovythao@hcmuaf.edu.vn

ABSTRACT

The use of drugs and chemicals in aquaculture has been increased surprisingly due to the fact that it has been moving from low to high level of intensification. However, there is lack of information in snakehead fish farming. The study was conducted by interviewing 65 farmers in Dinh Quan, Trang Bom, and Bien Hoa, Dong Nai province to provide sufficient information on the use of chloramphenicol (CAP) and amoxicillin (AMX) in snakehead fish farming. Interview results showed that no employment of the 2 antibiotics in prevention of diseases. However, CAP was currently applied to treat diseases at a concentration of 50.04 and $100.0 \mathrm{~g} /$ ton of fish in Bien Hoa and Trang Bom, respectively despite it was banned in aquaculture according to the law. AMX restricted to use was employed when fish got sick at 59.62, 91.49, and $89.58 \mathrm{~g} /$ ton of fish in Dinh Quan, Bien Hoa and Trang Bom, respectively. In contrast to field survey result, LC-MS/MS analysis of 3 fish muscle samples randomly collected at each place around 14 days before and on the day of harvesting indicated that no residue of concerned antibiotics was detected. The present study suggests that farmers currently apply antibiotics including banned antibiotics in fish but have initially raised awareness of the use of antibiotics, evidenced by the fact that they were only used when needed. Hence, the management and extension should be intensively promoted for a legal use of antibiotics and other chemicals.
\end{abstract}

Cited as: Ngo, T. V., Nguyen, P. Q., Ngo, L. D., \& Ngo, N. V. (2018). Investigation on the use of chloramphenicol and amoxicillin in snakehead fish (Channa maculata) farming and analysis of those antibiotic residue in muscle samples. The Journal of Agriculture and Development 17(4), $118-125$. 


\title{
Khảo sát hiện trạng sử dụng chất cấm (chloramphenicol) và kháng sinh hạn chế sử dụng (amoxicillin) trong quá trình nuôi cá lóc đầu nhím (Channa maculata) thương phẩm và phân tích dư lượng trong cơ thịt cá
}

\author{
Ngô Vy Thảo ${ }^{1 *}$, Nguyễn Quốc Phú ${ }^{1}, N_{\text {gô }}$ Đăng Lâm ${ }^{2}$ \& Ngô Văn Ngọc ${ }^{2}$ \\ ${ }^{1}$ Khoa Môi Trường và Tài Nguyên, Trường Đại Học Nông Lâm TP. Hồ Chí Minh, TP. Hồ Chí Minh \\ ${ }^{2}$ Khoa Thủy Sản, Trường Đại Học Nông Lâm TP. Hồ Chí Minh, TP. Hồ Chí Minh
}

\section{THÔNG TIN BÀI BÁO}

\section{Bài báo khoa học}

Ngày nhận: 08/03/2018

Ngày chỉnh sửa: 08/05/2018

Ngày chấp nhận: 05/07/2018

\section{Từ khóa}

Amoxicillin

Cá lóc

Chloramphenicol

Đồng Nai

LC-MS/MS

\section{*Tác giả liên hệ}

Ngô Vy Thảo

Email: ngovythao@hcmuaf.edu.vn

\section{TÓM TẮT}

Việc sử dụng thuốc và hóa chất trong nuôi trồng thủy sản (NTTS) ngày càng gia tăng đáng kể vì mức độ thâm canh ngày càng được nâng cao. Tuy nhiên, thông tin về nghề nuôi cá lóc hiện nay còn hạn chế. Nắm được nhu cầu trên, nghiên cứu được thực hiện nhằm đánh giá hiện trạng sử dụng hai loại kháng sinh $(\mathrm{KS})$ cấm (chloramphenicol, CAP) và hạn chế sử dụng (amoxicillin, $\mathrm{AMX}$ ) và kiểm tra dư lượng tồn động trên cơ thịt cá của hai loại KS này. Nghiên cứu tiến hành phỏng vấn 65 hộ nuôi cá ở Định Quán, Trảng Bom và Biên Hòa, Đồng Nai. Kết quả cho thấy không có việc sử dụng CAP và $\mathrm{AMX}$ trong phòng bệnh. Tuy nhiên, CAP vẫn được sử dụng để chữa bệnh ở mức 50,04 và 100,0 g/tấn cá ở Biên Hòa và Trảng Bom. AMX được sử dụng điều trị bệnh ở nồng độ 59,$62 ; 91,49$ và $89,58 \mathrm{~g} / \mathrm{tấn}$ cá ở Định Quán, Biên Hòa và Trảng Bom. Trái ngược với kết quả điều tra thực địa, phân tích hàm lượng kháng sinh trong 3 mẫu cá được thu ở mỗi khu vực khảo sát khoảng 14 ngày trước và ngay ngày thu hoạch cho thấy không có dư lượng KS được phát hiện. Nghiên cứu này cho thấy hiện nay nông dân có sử dụng KS, trong đó có kháng sinh cấm nhưng bước đầu đã nâng cao nhận thức về việc sử dụng kháng sinh, được minh chứng bằng thực tế là chúng chỉ sử dụng khi cần thiết. Do đó cần tăng cường việc quản lí và tăng cường công tác khuyến ngư để cung cấp kiến thức, thông tin cho nông dân sử dụng hợp pháp kháng sinh và các hóa chất khác trong NTTS.

\section{1. Đặt Vấn Đề}

Ngành nuôi trồng thủy sản (NTTS) ở Việt Nam hiện đang phát triển rất nhanh và có nhiều khởi sắc với tổng diện tích mặt nước NTTS là 1.072,2 nghìn ha (GSOV, 2017). Sản lượng NTTS năm 2016 ước tính đạt 3.640,6 nghìn tấn, trong đó sản lượng cá nuôi nước ngọt là 2.564,7 tấn tăng lần lượt là $3,1 \%$ và 1,5\% so với năm 2015 (GSOV, 2017). Đối với Đồng Nai, thuộc vùng Đông Nam Bộ, Việt Nam, khai thác thủy sản chưa phải là thế mạnh của vùng, tuy nhiên sản lượng NTTS những năm gần đây liên tục tăng, cụ thể là hơn 43 nghìn tấn ở 2014, hơn 45 nghìn tấn vào 2015 , và gần 48 nghìn tấn năm 2016 (GSOV, 2017) nhằm cung cấp cho các địa bàn lân cận như Thành phố Hồ Chí Minh, Bình Dương,...

Trong quá trình nuôi, nhiều loại hóa chất và thuốc kháng sinh (KS) được sử dụng để xử lí nước ao nuôi, bảo đảm chất lượng nước, phòng trị bệnh và tăng năng suất vật nuôi (Lan, 2013). Nông dân thường trộn thuốc vào thức ăn mà không tìm hiểu kỹ tác dụng cũng như tác hại của thuốc (Le \& ctv., 2015; Pham \& ctv., 2015). Tuy nhiên, năng suất này bắt đầu giảm và lợi nhuận dần biến mất từ một thập kỉ đổ lại đây (Nguyen \& Ford, 2010), dẫn đến tính bền vững trong NTTS không còn nữa. Ngoài ra, thức ăn dư thừa và phân có chứa thuốc KS có thể lắng xuống đáy và sau đó được dòng nước đưa sang khu vực lân cận (Boxall \& ctv., 2004; Miller \& Harbottle, 2018). Việc phát hiện dư lượng các chất KS trong thịt các loại thủy sản xuất khẩu cũng làm ảnh hưởng xấu tới nền kinh tế (Pham \& ctv., 2015). Thêm vào đó, nước nuôi chứa nhiều cặn bã, tạp chất, thuốc dư thừa trong suốt quá trình nuôi được thải trực tiếp ra ngoài không qua xử lí có thể làm ô nhiễm nguồn nước mặt khu vực xung quanh làm ảnh hưởng đến tính ổn định của nghề NTTS (Truong \& Tran, 2012). Đây cũng có thể là nguyên nhân 
tạo ra nhiều dòng vi khuẩn kháng $\mathrm{KS}$, đe dọa sức khỏe của con người và vật nuôi (Hoa \& ctv., 2011; Quach \& ctv., 2014).

Ở Việt Nam, chloramphenicol (CAP) và amoxicillin (AMX) là hai $\mathrm{KS}$ cấm và hạn chế sử dụng (MARD, 2009) do các tác hại của nó đối với sức khỏe con người và môi trường (De Francesco \& ctv., 2010; Dowling, 2013). Dù vậy, qui định này chỉ khắt khe cho sản phẩm thủy sản xuất khẩu, còn với hàng tiêu thụ nội địa thì việc kiểm tra qui trình nuôi, chế biến và bảo quản vẫn còn bỏ ngỏ. Hiện nay các nghiên cứu trên thế giới và ở Việt Nam về việc sử dụng thuốc và dư lượng $\mathrm{KS}$ (DLKS) ở cá nước ngọt chủ yếu tập trung vào cá tra và cá ba sa (Ang \& ctv., 2000; CañadaCañada \& ctv., 2009; Quach \& ctv., 2014). Cá lóc đầu nhím (Channa maculata) là một loại cá lóc Việt Nam, thịt trắng, ngọt, rất được ưa chuộng với người tiêu dùng (Vu \& Nguyen, 2005). Cũng giống như các loại NTTS khác, trong quá trình nuôi cá lóc thương phẩm, người nông dân không tránh khỏi việc sử dụng thuốc và hóa chất để vệ sinh ao, phòng và trị bệnh (Le \& Do, 2009) nhưng những thông tin mang tính chất khoa học về quá trình nuôi loài cá này rất hạn chế. Do đó, nghiên cứu được thực hiện nhằm mục đích cung cấp thông tin về việc sử dụng hai loại KS nói trên tại các trại nuôi cá lóc thương phẩm ở Đồng Nai, cũng như phân tích DLKS có trong cơ thịt cá. Kết quả nghiên cứu có thể làm cơ sở để các nhà chức trách phối hợp cùng các cơ quan chức năng quản lí và kiểm soát việc sử dụng $\mathrm{KS}$, cũng như làm tiền đề cho các nghiên cứu tiếp theo nhằm hạn chế các ảnh hưởng đến môi trường và đảm bảo tính bền vững của nghề nuôi cá lóc nói riêng và NTTS nói chung.

\section{Vật Liệu và Phương Pháp Nghiên Cứu}

\section{1. Địa điểm khảo sát và thu mẫu}

Ba huyện/thành phố thuộc tỉnh Đồng Nai là Định Quán, Trảng Bom, và Biên Hòa được lựa chọn để tiến hành khảo sát và thu mẫu cá (Hình 1). Đây là những khu vực có nhiều hộ nuôi cá lóc gần với thành phố Hồ Chí Minh (TP.HCM) tiện lợi cho nghiên cứu.

\subsection{Phân tích DLKS (CAP và AMX) trong cơ thị cá}

Việc thu mẫu cá được tiến hành như sau. Chọn ngẫu nhiên 01 hộ nuôi cá lóc thương phẩm ở mỗi



Hình 1. Vị trí tỉnh Đồng Nai ở Việt Nam $\left(11^{0} 7^{\prime} \mathrm{N}\right.$ $\left.107^{0} 11^{\prime} \mathrm{E}\right)$ và vị trí Định Quán, Trảng Bom và Biên Hòa trong tỉnh Đồng Nai (Được chỉnh sửa từ www.dongnai.gov.vn).

địa điểm điều tra Định Quán, Trảng Bom và Biên Hòa. Tại thời điểm khoảng 14 ngày trước và khi thu hoạch cá, 03 cá thể cá được thu ngẫu nhiên tại mỗi hộ trên. Theo (Wang \& ctv., 2004; Nguyen \& Phung, 2010; Ansari \& ctv., 2014) và kinh nghiệm của các chuyên gia NTTS thì thời gian 14 ngày là khoảng thời gian cách li đủ để bài thải hoàn toàn tồn dư KS trong cơ thịt cá. Việc khảo sát DLKS tại hai thời điểm trước và khi thu hoạch nhằm kiểm tra xem người nông dân có thực hành theo đúng khuyến cáo của các chuyên gia hay không. Cá sau khi thu sống được vận chuyển kín về phòng thí nghiệm. Tại đây, cá được đánh sạch vảy, phi lê, lóc lấy phần thịt từ lưng tới đuôi có khối lượng từ 50 tới $100 \mathrm{~g}$ và trữ đông ở $-20^{\circ} \mathrm{C}$ cho tới khi được gửi đi phân tích DLKS. Đặc điểm sinh học của cá thể cá làm mẫu được thể hiện trong Bảng 1 . Chỉ tiêu môi trường nước ao nuôi lấy mẫu được đo bằng test kit SERA (Đức) và mô tả trong Bảng 2.

Dư lượng $\mathrm{CAP}$ và $\mathrm{AMX}$ được định lượng tại Trung tâm Dịch vụ phân tích thí nghiệm TP.HCM (Số 02 Đường Nguyễn Văn Thủ, Đa Kao, Quận 1, Hồ Chí Minh) trên hệ thống LCMS/MS lần lượt theo (Neuhaus \& ctv., 2002) và (Becker \& ctv., 2004). Ngưỡng phát hiện của CAP và $\mathrm{AMX}$ là 0,05 và $15 \mu \mathrm{g} / \mathrm{kg}$, phù hợp với MARD (2009).

\section{Kết Quả và Thảo Luận}

\section{1. Đặc điểm chung của các hộ được khảo sát}

Qua kết quả điều tra thực tế 65 hộ dân nuôi cá lóc đầu nhím thâm canh, số nhân khẩu tham 
Bảng 1. Đặc điểm sinh học của cá thể cá lóc lấy mẫu tại các địa điểm

\begin{tabular}{ccccc}
\hline Tên mẫu cá & Thời gian lấy mẫu & Nơi lấy mẫu & Khối lượng $(\mathrm{g})$ & Chiều dài $(\mathrm{cm})$ \\
\hline DQ1 & $29 / 10 / 2016^{*}$ & Định Quán & 860 & 42 \\
DQ2 & $29 / 10 / 2016^{*}$ & Định Quán & 700 & 38 \\
DQ3 & $29 / 10 / 2016^{*}$ & Định Quán & 450 & 32 \\
DQ4 & $12 / 11 / 2016^{\dagger}$ & Định Quán & 900 & 44 \\
DQ5 & $12 / 11 / 2016^{\dagger}$ & Định Quán & 700 & 41 \\
DQ6 & $12 / 11 / 2016^{\dagger}$ & Định Quán & 600 & 37 \\
TB1 & $03 / 11 / 2016^{*}$ & Trảng Bom & 700 & 40 \\
TB2 & $03 / 11 / 2016^{*}$ & Trảng Bom & 240 & 31 \\
TB3 & $03 / 11 / 2016^{*}$ & Trảng Bom & 450 & 35 \\
TB4 & $18 / 11 / 2016^{\dagger}$ & Trảng Bom & 400 & 34 \\
TB5 & $18 / 11 / 2016^{\dagger}$ & Trảng Bom & 400 & 33 \\
TB6 & $18 / 11 / 2016^{\dagger}$ & Trảng Bom & 300 & 29 \\
BH1 & $03 / 11 / 2016^{*}$ & Biên Hòa & 300 & 33 \\
BH2 & $03 / 11 / 2016^{*}$ & Biên Hòa & 500 & 40 \\
BH3 & $03 / 11 / 2016^{*}$ & Biên Hòa & 400 & 36 \\
BH4 & $18 / 11 / 2016^{\dagger}$ & Biên Hòa & 400 & 39 \\
BH5 & $18 / 11 / 2016^{\dagger}$ & Biên Hòa & 450 & 41 \\
BH6 & $18 / 11 / 2016^{\dagger}$ & Biên Hòa & 500 & 41 \\
\hline
\end{tabular}

*Thời điểm trước khi thu hoạch, ${ }^{\dagger}$ Thời điểm ngay lúc thu hoạch.

Bảng 2. Chỉ tiêu nguồn nước tại ao nuôi lấy mẫu

\begin{tabular}{ccccc}
\hline Cịa điểm & Ngày lấy mẫu & $\mathrm{pH}$ & $\begin{array}{c}\mathrm{DO} \\
(\mathrm{mg} / \mathrm{L})\end{array}$ & $\begin{array}{c}\mathrm{NH}_{3} / \mathrm{NH}_{4}^{+} \\
(\mathrm{mg} / \mathrm{L})\end{array}$ \\
\hline \multirow{2}{*}{ Định Quán } & $29 / 10 / 2016^{*}$ & 7,4 & 4 & 0,06 \\
& $12 / 11 / 2016^{\dagger}$ & 7,4 & 4 & 0,06 \\
\hline \multirow{2}{*}{ Trảng Bom } & $03 / 11 / 2016^{*}$ & 7,3 & 4 & 0,06 \\
& $18 / 11 / 2016^{\dagger}$ & 7,3 & 4 & 0,06 \\
\hline \multirow{2}{*}{ Biên Hòa } & $03 / 11 / 2016^{*}$ & 7,3 & 4 & 0,06 \\
& $18 / 11 / 2016^{\dagger}$ & 7,3 & 4 & 0,06 \\
\hline
\end{tabular}

*Thời điểm trước khi thu hoạch, ${ }^{\dagger}$ Thời điểm ngay lúc thu hoạch.

gia nuôi cá lóc trung bình là 4,2 người/hộ (kể cả lao động thuê). Phần lớn chủ hộ nuôi cá và người tham gia nuôi cá là nam giới. Còn nữ giới chỉ phụ giúp một số công việc nhẹ hoặc nội trợ. Đây cũng là đặc thù của hầu hết các vùng thâm canh NTTS (Nguyen, 2017). Nguyên nhân của sự hạn chế tham gia vào công việc này ở nữ giới có thể do trình độ học vấn và kĩ thuật thấp, điều kiện sức khỏe không phù hợp. Độ tuổi của chủ hộ phần lớn từ 45 đến 55 tuổi, với độ tuổi này phản ánh kinh nghiệm NTTS tương đối cao nhưng hạn chế về mặt thay đổi thói quen NTTS, đa số còn giữ những kinh nghiệm canh tác lỗi thời, không phù hợp với kiến thức khoa học thời đại mới, gây khó khăn cho công tác khuyến ngư. Bên cạnh đó, trình độ học vấn là một trong những yếu tố quyết định đến khả năng tiếp thu các kiến thức cũng như chọn lọc và vận dụng vào sản xuất cho phù hợp với điều kiện thực tế, quyết định được khả năng điều hành các hoạt động sản xuất cho chính xác. Kết quả điều tra cho thấy phần lớn trình độ văn hóa của chủ hộ là cấp 2 - 3, chiếm $93,2 \%$ (Bảng 3).

Tất cả các hộ dân $(65 / 65$ hộ) dều cho biết họ nuôi cá dựa trên kinh nghiệm đúc kết và hướng dẫn của nhân viên tiếp thị hoặc đại lí bán thuốc/thức ăn thủy sản. Điều này chứng tỏ công tác khuyến ngư và truyền bá kiến thức NTTS chưa được sâu sát và chưa nhận được sự quan tâm đúng mức của người dân.

Bảng 4 cho thấy diện tích đất thâm canh NTTS mỗi hộ dân ở khu vực khảo sát là không đồng đều. Có 39 hộ (09 hộ ở Trảng Bom và 30 hộ ở Biên Hòa) không có số liệu do quá trình điều tra có sơ sót vì bị giới hạn về mặt thời gian phỏng vấn. 
Bảng 3. Trình độ học vấn của chủ hộ

\begin{tabular}{ccc}
\hline Trình độ & Số lượng (hộ) & Tỉ lệ (\%) \\
\hline Cấp 1 & 4 & 6,2 \\
Cấp 2 & 26 & 40,0 \\
Cấp 3 & 34 & 52,3 \\
Trung học chuyên nghiệp trở lên & 1 & 1,5 \\
Tổng & 65 & 100 \\
\hline
\end{tabular}

Bảng 4. Tình trạng đất nuôi cá của các nông hộ

\begin{tabular}{cccccc}
\hline Hạng mục & Dưới 10 ha & $10-15$ ha & Trên 15 ha & Không số liệu & Tổng \\
\hline Số lượng (hộ) & 13 & 5 & 8 & 39 & 65 \\
Tỉ lệ $(\%)$ & 20 & 8 & 12 & 60 & 100 \\
\hline
\end{tabular}

3.2. Tình hình sử dụng $\mathrm{CAP}$ và $\mathrm{AMX}$ trong quá trình nuôi cá thương phẩm

Kết quả điều tra cho thấy trong 65 hộ, không có hộ nào sử dụng hai loại KS này trong quá trình phòng bệnh. Tình hình sử dụng $2 \mathrm{KS} \mathrm{CAP}$ và AMX để trị bệnh của 65 hộ dân được tóm tắt tại Bảng 5. Trong đó, 49,23\% hộ (32/65 hộ) sử dụng CAP và $98,46 \%$ hộ $(64 / 65$ hộ) sử dụng $\mathrm{AMX}$ để trị bệnh cho cá. Đáng chú ý ở kết quả là tất cả số hộ được phỏng vấn ở Định Quán (26/26 hộ) đều không sử dụng CAP trong suốt quá trình nuôi.

KS được trộn vào thức ăn cho cá. Người dân sử dụng CAP để điều trị các bệnh thường gặp ở cá như đỏ mỏ, đỏ kỳ, xuất huyết và gan thận mủ xuất hiện từ tháng thứ 2 tới tháng thứ 5 trong quá trình nuôi. AMX thì được dùng chữa các bệnh tương tự như CAP và thêm đốm đỏ, trắng mình xuất hiện hàng tháng từ tháng thứ 3 . Hiệu quả trị bệnh ghi nhận từ phỏng vấn là 50 - $80 \%$ và $70-100 \%$ đối với CAP và $A M X$. Hiệu quả điều trị cao, cộng với việc tần suất cá mắc bệnh dày (hầu như tháng nào cũng gặp) có thể là nguyên nhân khiến cho AMX được tin dùng rộng rãi hơn trong nghiên cứu này. AMX cũng là một trong những loại KS được dùng phổ biến trong nuôi cá tra thâm canh (Long và ctv., 2014).

Hình 2 cho thấy rõ sự khác biệt giữa liều lượng KS sử dụng ở 3 khu vực. Nhìn chung, khu vực Định Quán dùng KS ít nhất, họ không sử dụng CAP, lượng AMX sử dụng cũng ít nhất với 59,62 $\pm 14,84 \mathrm{~g} /$ tấn cá (giá trị trung bình \pm sai số). Hai khu vực còn lại sử dụng cả 2 loại KS, trong đó khu vực Biên Hòa sử dụng liều lượng KS cao nhất với $50,00 \pm 5,87 \mathrm{~g} \mathrm{CAP} /$ tấn cá và $91,49 \pm$ 18,27 g AMX/tấn cá. Ở Trảng Bom, người dân sử dụng liều lượng 100,0 g CAP/tấn cá và 89,58
土 15,27 g AMX/tấn cá. Thực chất, ở Trảng Bom, chỉ có 01 hộ (trong 09 hộ được phòng vấn) có xài CAP (nồng độ $100 \mathrm{~g} /$ tấn cá) và có 01 hộ (trong 09 hộ phỏng vấn) không xài AMX để trị bệnh cá, cho nên số liệu trung bình trên biểu đồ của CAP chỉ tính cho 01 hộ, và của $\mathrm{AMX}$ là tính cho 8/9 hộ.

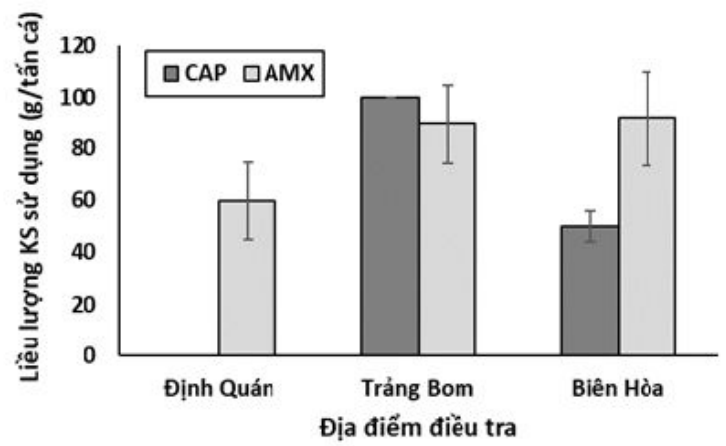

Hình 2. Liều lượng $\mathrm{KS}$ sử dụng trong điều trị bệnh cả ở ba khu vực khảo sát. Liều lượng CAP được thể hiện bằng cột màu xám đậm và liều lượng $\mathrm{AMX}$ là cột xám nhạt. Giá trị liều lượng mỗi KS sử dụng thể hiện giá trị trung bình của các liều lượng $\mathrm{KS}$ tương ứng mà các hộ dân được phỏng vấn trong cùng khu vực khảo sát sử dụng. Thanh sai số thể hiện độ lệch chuẩn $(\mathrm{SD})$.

Theo thông tin của các chuyên gia trong ngành NTTS tại trường Đại học Nông Lâm TP.HCM, hiện nay các công ty sản xuất thức ăn và thuốc thủy sản lớn đều tuân thủ qui định về KS trong kinh doanh thức ăn và thuốc, vì vậy nhân viên bán hàng của các công ty đều thông tin tới người dân và hướng dẫn họ hướng tới sử dụng các thuốc trị bệnh có nguồn gốc từ thiên nhiên, ví dụ như chiết xuất từ tỏi (Hình 3 ). Tuy nhiên, tình hình tuân thủ qui định ở các cơ sở sản xuất nhỏ lẻ 
Bảng 5. Số hộ sử dụng $\mathrm{CAP}$ và $\mathrm{AMX}$ trong điều trị bệnh cá

\begin{tabular}{ccccccc}
\hline \multirow{2}{*}{ KS } & \multicolumn{2}{c}{ Có sử dụng } & \multicolumn{2}{c}{ Không sử dụng } & \multicolumn{2}{c}{ Tổng } \\
\cline { 2 - 7 } & Số lượng (hộ) & Tỉ lệ $(\%)$ & Số lượng (hộ) & Tỉ lệ $(\%)$ & Số lượng (hộ) & Tỉ lệ (\%) \\
\hline CAP & 32 & 49,23 & 33 & 50,77 & 65 & 100 \\
AMX & 64 & 98,46 & 01 & 1,54 & 65 & 100 \\
\hline
\end{tabular}

lại chưa được nắm rõ và cần điều tra trong các nghiên cứu tiếp theo. Hiện trạng này rất phù hợp với kết quả khảo sát về kinh nghiệm NTTS. Kết quả có thể cho thấy người nuôi cá bước đầu có hiểu biết về qui định sử dụng $\mathrm{KS}$, biết được $\mathrm{KS}$ nào cấm sử dụng nhờ vào thông tin từ nhân viên tiếp thị của các công ty thức ăn và thuốc, từ đó hạn chế đưa vào sử dụng, và chỉ sử dụng khi họ thấy cần thiết (tức lúc cá bị bệnh). So với những nghiên cứu thực hiện gần đây cho thấy người dân chưa có nhận thức và hiểu biết nhiều về việc sử dụng KS (Long \& ctv., 2014; Le \& ctv., 2015) thì nghiên cứu hiện tại cho kết quả khởi sắc hơn.

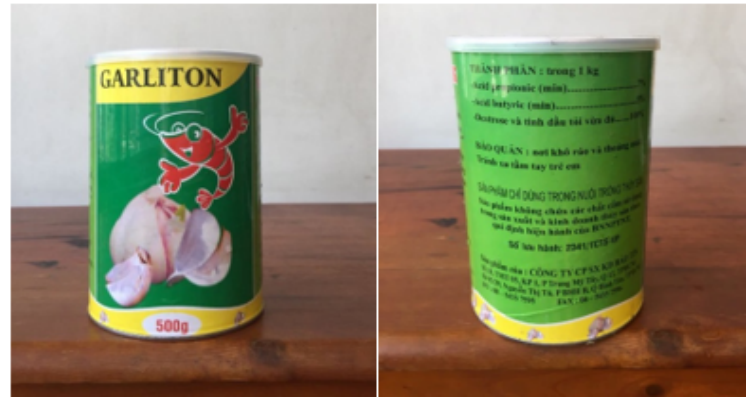

Hình 3. Một sản phẩm thuốc có chiết xuất từ tỏi và không chứa các chất cấm sử dụng dùng trong NTTS đang được bán trên thị trường với số lưu hành 2341/TCTS-VP, có tác dụng phòng và trị bệnh đường tiêu hóa trên cá, tôm.

CAP và AMX theo đánh giá của Tổ chức $\mathrm{Y}$ tế thế giới (WHO) là loại KS rất quan trọng (highly important) và cực kì quan trọng (critically important) (WHO, 2017). Tiêu chí để đánh giá tầm quan trọng của KS là (1) loại KS này là duy nhất, hoặc là một trong số ít những phương pháp trị liệu, để chữa nhiễm khuẩn nặng ở người; và (2) loại KS này được sử dụng để điều trị nhiễm trùng ở người do một trong hai nguyên nhân sau: (i) vi khuẩn có thể lây truyền cho người từ các nguồn không phải của con người, hoặc (ii) vi khuẩn có thể nhận được gen kháng bệnh từ nguồn không phải của con người. CAP được xếp là KS rất quan trọng vì đạt tiêu chí (2) nhưng không đạt tiêu chí (1), trong khi đó AMX đạt đủ hai tiêu chí. Điều này có thể chứng tỏ rằng $\mathrm{CAP}$ không phải là loại
KS duy nhất có thể sử dụng để điều trị các loại bệnh cá đề cập ở trên. Vì vậy việc không dùng CAP trong NTTS là điều khả thi, và cần tìm ra các phương pháp khác để thay thế như chỉ sử dụng các loại KS trong danh mục cho phép sử dụng theo hướng dẫn kĩ thuật, sử dụng các thuốc có nguồn gốc từ tự nhiên hoặc chứa chiết xuất tự nhiên (Hình 3 ). và phổ biến rộng rãi hơn nữa thông tin tới người dân.

\subsection{Dư lượng kháng sinh trong cơ thị cá}

Tổng cộng có 09 mẫu cá trước khi thu hoạch và 09 mẫu cá ngay khi thu hoạch được đem đi phân tích DLKS CAP và AMX trong cơ thịt (Bảng 1). Kết quả phân tích cho thấy không phát hiện DLKS của cả hai loại KS trong cơ thịt cá. Nhiều thực tế có thể là nguyên nhân dẫn đến kết quả này. Thứ nhất, số cá thể lấy mẫu là quá ít (03 cá thể cá tại mỗi địa điểm) do giới hạn về mặt kinh phí của nghiên cứu. Theo một nghiên cứu khác về DLKS trên cá ở Việt Nam, tỉ lệ phát hiện DLKS ở thịt cá chiếm 11\% (Pham \& ctv., 2015) với kích thước mẫu lớn (51 cá thể). Thứ hai, tại thời điểm thu mẫu cá, tác giả nhận thấy cá không bị bệnh. Đối chiếu với kết quả phỏng vấn cho thấy người dân chỉ sử dụng KS khi cá bị bệnh, nên xác suất phát hiện DLKS trên cơ thịt thấp. Thứ ba, CAP và $A M X$ là hai loại $K S$ có chu kì bán rã ngắn, lần lượt là 13,5 giờ và 61,3 phút (Gordon \& ctv., 1972; Nguyen \& Phung, 2010). Theo đó, thời gian để bài thải hoàn toàn CAP ra khỏi cơ thể tôm được thí nghiệm là 120 giờ. Cuối cùng, độ nhạy của phép phân tích có thể là một nguyên nhân cho sự không phát hiện DLSK (ngưỡng phát hiện của CAP và $A M X$ là 0,05 và $15 \mu \mathrm{g} / \mathrm{kg}$ ). Kết quả phân tích DLKS một lần nữa khẳng định lại nhận định về hiện trạng nhận thức của người nuôi cá đối với việc sử dụng KS. Tuy nhiên, cần tiến hành nghiên cứu với kích thước mẫu lớn hơn, ở nhiều địa điểm hơn và phân tích dư lượng của các KS thường hay sử dụng khác, như enrofloxacine, trimethoprime, và sulfadimethoxine, ... (Le \& ctv., 2015) nhằm cung cấp bảng dữ liệu nền đầy đủ cho ngành nuôi cá lóc ở Việt Nam, giúp cho việc quản lí và định hướng phát triển ngành nghề này trong tương lai. 


\section{Kết Luận}

Nghiên cứu này đã xác định được hiện trạng sử dụng hai loại $\mathrm{KS}$ cấm $(\mathrm{CAP})$ và hạn chế sử dụng (AMX) trong các ao nuôi cá lóc thâm canh tại huyện Định Quán, Trảng Bom và thành phố Biên Hòa, tỉnh Đồng Nai. Trong quá trình nuôi, người nuôi cá không sử dụng hai loại KS này để phòng bệnh, nhưng có sử dụng để trị bệnh cá. Kết quả phân tích DLKS của CAP và $A M X$ trong cơ thịt cá cũng cho thấy không có lượng tồn dư nào được phát hiện. Nghiên cứu còn phản ánh sự hạn chế của người nuôi trong quá trình tiếp cận thông tin về kĩ thuật nuôi, sử dụng thuốc và hóa chất, cũng như các qui định của pháp luật liên quan tới ngành. Cần triển khai các nghiên cứu tiếp theo khảo sát việc sử dụng tất cả các loại thuốc và hóa chất trong suốt quá trình nuôi trên diện rộng, cũng như đánh giá sự tồn lưu thuốc và hóa chất trong ao nuôi, và trong cơ thịt cá lóc nhằm cung cấp dữ liệu nền và làm cơ sở đề xuất giải pháp giảm các tác động xấu đến môi trường và đảm bảo tính bền vững của nghề nuôi cá lóc thâm canh.

\section{Lời Cảm Ơn}

Nghiên cứu này được tài trợ bởi kinh phí đề tài khoa học và công nghệ cấp cơ sở mã số CSCB16-MTTN-03 của trường Đại học Nông Lâm TP.HCM. Nhóm nghiên cứu chân thành cám ơn Hợp tác xã Vĩnh Hưng, Biên Hòa, Đồng Nai và nhân viên tiếp thị công ty GREENFEED Việt Nam ở Định Quán, Đồng Nai đã hỗ trợ nhóm nghiên cứu trong quá trình phỏng vấn và thu mẫu cá để chúng tôi có thể hoàn thành nghiên cứu này.

\section{Tài Liệu Tham Khảo (References)}

Ang, Y. W. C., Liu, F. F., Lay, O. J., Luo, W., McKim, K., Gehring, T., \& Lochmann, R. (2000). Liquid chromatographic analysis of incurred amoxicillin residues in catfish muscle following oral administration of the drug. Journal of agricultural and food chemistry 48(5), 1673-1677.

Ansari, M., Raissy, M., \& Rahimi, E. (2014). Determination of florfenicol residue in rainbow trout muscles by HPLC in Chaharmahal va Bakhtiari Province, Iran. Comparative Clinical Pathology 23(1), 61-62.

Becker, M., Zittlau, E., \& Petz, M. (2004). Residue analysis of 15 penicillins and cephalosporins in bovine muscle, kidney and milk by liquid chromatographytandem mass spectrometry. Analytica Chimica Acta 520(1-2), 19-32.
Boxall, B. A. A., Fogg, L. A., Blackwell, P. A., Blackwell, P., Kay, P., Pemberton, E. J., \& Croxford, A. (2004). Veterinary medicines in the environment. In Voogt, P. (Ed.). Reviews of environmental contamination and toxicology (ed., 1-91). New York, USA: Springer.

Cañada-Cañada F., Muñoz de la Peña, A., \& EspinosaMansilla, A. (2009). Analysis of antibiotics in fish samples. Analytical and bioanalytical chemistry 395(4), 987-1008.

De Francesco, V., Giorgio, F., Hassan, C., Manes, G., Vannella, L., Panella, C., Ierardi, E., \& Zullo, A. (2010). Worldwide H. pylori antibiotic resistance: a systematic review. Journal of Gastrointestinal \& Liver Diseases 19(4), 409-414.

Dowling, P. M. (2013). Chloramphenicol, thiamphenicol, and florfenicol. In Steeve Giguère, S., Prescott, J. F., \& Dowling, P. M (Eds.). Antimicrobial Therapy in Veterinary Medicine (5 ${ }^{\text {th }}$ ed., 269-277). New Jersey, USA: Wiley-Blackwell.

Gordon, C. R., Regamey, C., \& Kirby, M. M. W. (1972). Comparative clinical pharmacology of amoxicillin and ampicillin administered orally. Antimicrobial agents and chemotherapy 1(6), 504-507.

Hoa, P. T. P., Managaki, S., Nakada, N., Takada, H., Shimizu, A., Anh, D. H., Viet, P. H., \& Satoru, S. (2011). Antibiotic contamination and occurrence of antibiotic-resistant bacteria in aquatic environments of northern Vietnam. Science of the Total Environment 409(15), 2894-2901.

Lan, N. T. P. (2013). Social and ecological challenges of market-oriented shrimp farming in Vietnam. SpringerPlus 2(1), 675.

Le, L. M., Hans, B., \& Ngo, T. T. D. (2015). Chemicals and drugs use in intensive striped catfish (Pangasianodon hypophthamus) culture in Dong Thap province, Vietnam. Can Tho University Journal of Science, 1825 .

Le, X. S., \& Do, C. M. (2009). Investigation of snakehead culture models (Channa micropelte and Channa striata) at the Mekong Delta. Proceeding of International Science in Aquaculture (436-447). Ho Chi Minh, Vietnam: Nong Lam University, Ho Chi Minh City.

Long, L. M., Hans, B., Huong, D. T. T., \& Trang, N. T. D. (2014). Status of chemical and antibiotic use in intensive catfish Pangasianodon hypophthamus farms in Can Tho city, Vietnam. Journal of Science and Technology 52(3A), 330-335.

MARD (Ministry of Agriculture and Rural Development). (2009). List of drugs, chemicals and antibiotics banned from use or restricted use. Ha Noi, Vietnam: Office of the Ministry of Agriculture and Rural Development.

Miller, A. R., \& Harbottle, H. (2018). Antimicrobial drug resistance in fish pathogens. Microbiology spectrum 6(1), 1-20.

Neuhaus, K. B., Hurlbut, A. J., \& Hammack, W. (2002). LC/MS/MS analysis of chloramphenicol in shrimp. Laboratory Information Bulletin 4290, 1-13. 
Nguyen, D. T., \& Phung, H. V. C. (2010). Evaluation of elimination of chloramphenicol in tiger shrimp ( $P e$ naeus monodon) under experimental conditions using LC/MS/MS. National Biotechnology Conference in Southern Vietnam, (ed., 149-152). Ho Chi Minh City, Vietnam: Vietnam Technology Publication.

Nguyen, Q. T. K. (2017). Labor division and roles of gender in aquaculture: a case study on improved extensive farming model of black tiger shrimp (Penaeus monodon) in Bac Lieu province. Can Tho University Journal of Science, 51, 64-73.

Nguyen, T. H. T., \& Ford, A. (2010). Learning from the neighbors: economic and environmental impacts from intensive shrimp farming in the Mekong Delta of Vietnam. Sustainability 2(7), 2144-2162.

Pham, K. D., Chu, J., Do, T. N., Brose, F., Degand, G., Delahaut, P., De Pauw E., Douny, C., Nguyen, K. V., \& Vu, D. T. (2015). Monitoring antibiotic use and residue in freshwater aquaculture for domestic use in Vietnam. EcoHealth 12(3), 480-489.

Quach, T. V. C., Tu, D. T., \& Pham, D. H. H. (2014). The current status antimicrobial resistance in $E d$ wardsiella ictaluri and Aeromonas hydrophila cause disease on the striped catfish farmed in the Mekong Delta. Can Tho University Journal of Science 2, 7-14.
GSOV (General Statistics Office of Vietnam). (2017). Argro-forestry and Aquaculture (Statistical yearbook 2016). Ha Noi, Viet Nam: Statistical Publishing House.

Truong, P. Q., \& Tran, T. K. (2012). Chemical compositions of sludge from intensive striped catfish (Pangasianodon hypophthalmus) culture pond. Can Tho University Journal of Science 22a, 290-299.

Vu, T. T., \& Nguyen, M. D. (2005). Ichthyology. Ho Chi Minh, Vietnam: Agricultural Publishing House.

Wang, W., Lin, H., Xue, C., \& Khalid, J. (2004). Elimination of chloramphenicol, sulphamethoxazole and oxytetracycline in shrimp, Penaeus chinensis following medicated-feed treatment. Environment International 30(3), 367-373.

WHO (World Health Organization). (2017). Critically important antimicrobials for human medicine: ranking of antimicrobial agents for risk management of antimicrobial resistance due to non-human use. Geneva, Switzerland: WHO Document Production Services. 